\title{
Loss Distribution Analysis of a Three-Port Converter for Low-Power Stand-Alone Light- to-Light Systems
}

Mira Albert, Maria del Carmen; Knott, Arnold; Andersen, Michael A. E.

Published in:

Proceedings of the 18th Conference on Power Electronics and Application

Link to article, DOI:

10.1109/EPE.2016.7695630

Publication date:

2016

Document Version

Peer reviewed version

Link back to DTU Orbit

Citation (APA):

Mira Albert, M. D. C., Knott, A., \& Andersen, M. A. E. (2016). Loss Distribution Analysis of a Three-Port Converter for Low-Power Stand-Alone Light-to-Light Systems. In Proceedings of the 18th Conference on Power Electronics and Application IEEE. https://doi.org/10.1109/EPE.2016.7695630

\section{General rights}

Copyright and moral rights for the publications made accessible in the public portal are retained by the authors and/or other copyright owners and it is a condition of accessing publications that users recognise and abide by the legal requirements associated with these rights.

- Users may download and print one copy of any publication from the public portal for the purpose of private study or research.

- You may not further distribute the material or use it for any profit-making activity or commercial gain

- You may freely distribute the URL identifying the publication in the public portal 


\title{
Loss Distribution Analysis of a Three-Port Converter for Low-Power Stand-Alone Light-to-Light Systems
}

\author{
Maria C. Mira, Arnold Knott, Michael A. E. Andersen \\ Dept. Electrical Engineering, Technical University of Denmark \\ Elektrovej, 325 \\ Kongens Lyngby, Denmark \\ Email:mmial@elektro.dtu.dk, akn@elektro.dtu.dk,ma@elektro.dtu.dk \\ URL: http://www.ele.elektro.dtu.dk/
}

\section{Keywords}

$\ll$ Three-Port Converter (TPC)》, «photovoltaic (PV)》, «light-emitting diode (LED)》, «standalone $\gg, \ll$ high efficiency $\gg$.

\begin{abstract}
In locations far from the equator achieving high conversion efficiency in low-power solar systems is challenging due to low solar irradiance levels. This paper presents a high efficiency three-port converter (TPC) for light-to-light (LtL) applications where no direct solar conversion is required. The separation of the power flows allows to replace the conventional solution of two cascaded converters into a single structure with shared components. A loss distribution analysis of the proposed structure is performed, which shows very good match with the experimental results. A prototype of the TPC demonstrates high efficiency in both power flow paths. At low irradiation level, the photovoltaic to battery stage shows a peak efficiency of $99.1 \%$ at at $1.5 \mathrm{~W}$ output power and the LED driver stage presents a peak efficiency of $97.3 \%$ at $3 \mathrm{~W}$ output power.
\end{abstract}

\section{Introduction}

Renewable energy systems play an important role in order to overcome carbon dioxide emissions $\left(\mathrm{CO}_{2}\right)$ and fossil fuel resources depletion. Furthermore, due to the ability to generate off-grid electricity, sustainable energy systems have attracted research interest in the last decades [1]. Switched-mode power supplies (SMPS) are a key part of the integration of renewable energy systems due to the importance of high energy conversion [2]. Solar energy is one of the major renewable energy sources because it is unlimited, clean and free. However, because of the intermittent nature of the energy source, solar systems need to be combined with an energy storage element. The energy storage turns the assembly into a stand-alone system, which is very useful to power up systems both at remote locations and in the urban environment, completely eliminating the cost of cabling and construction.

The application under analysis is a light-to-light (LtL) solar powered LED lighting system. Photovoltaic (PV) technology converts the sunlight into electricity, and the generated output power depends on the amount of solar irradiation, which strongly depends on the location and the weather conditions. This is particularly a drawback during winter in northern latitudes, where the length of the day is short and the amount of solar irradiation is very low, as it can be observed in Fig. 1 where the annual solar irradiance pattern in a northern latitude is shown [3]. This fact together with the low energy conversion efficiency of PV panels, which is around 18-20\% for multicrystalline Silicon ( $\mathrm{Si}$ ) cells [4], makes high efficiency conversion a critical aspect especially in solar powered applications.

Light-emitting diode (LED) technology is gradually replacing conventional lighting systems towards solid-state lighting (SSL) systems due to significantly higher luminous efficacy and longer lifetime $[5,6]$. 


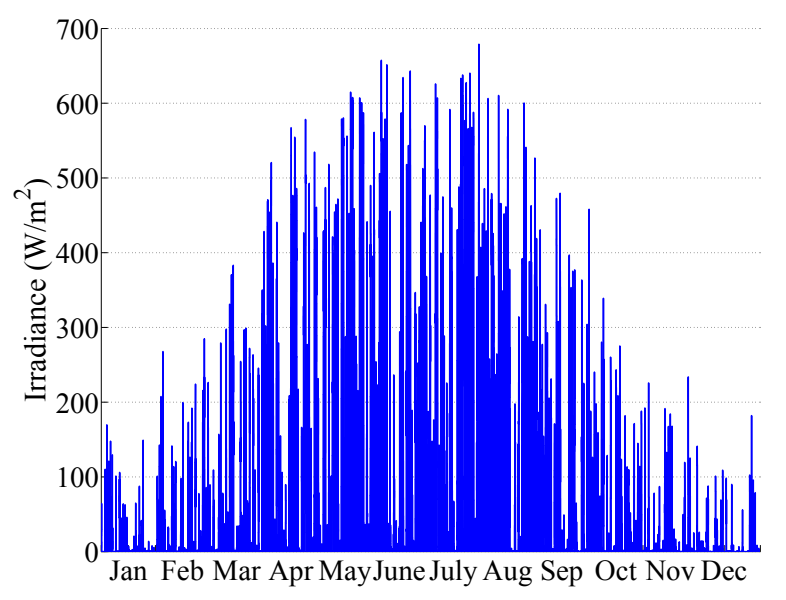

Fig. 1: Annual solar irradiation pattern in a northern latitude [3].

To provide sufficient output illumination single LEDs are combined into arrays to form LED lamps. In high-brightness applications, series connection is usually adopted in order to avoid mismatch in the current of parallel connected LEDs [7, 8, 9] due to devices characteristic $I-V$ curve and temperature variation. Moreover, due to the phenomenon known as efficiency droop, where LED efficacy decays at high current values, in order to achieve high luminous efficiency, LED strings are typically driven at a low current level, which increases the number of required LEDs for the same luminous output. In lowvoltage low-power stand-alone battery applications, these two characteristics makes necessary a high step-up power converter in order to drive a large number of series-connected LEDs.

In locations far from the equator, low-power photovoltaic systems are challenging due to the intrinsic limitations of the geographic location. This paper presents a high efficiency TPC to interconnect with PV panels, energy storage and LEDs for street lightning applications, where no direct solar conversion is required. In order to investigate each component contribution to the total loss, a loss distribution analysis is performed and the theoretical results are compared to the experimental efficiency measurements.

\section{System Specifications}

The input port of the LtL system is composed of two PV panels connected in parallel with a maximum power of $P_{m p}=10.92 \mathrm{~W}, V_{m p}=6.50 \mathrm{~V}, I_{m p}=1.68 \mathrm{~A}, V_{o c}=8.10 \mathrm{~V}, I_{s c}=1.86 \mathrm{~A}$. Fig. $2 \mathrm{a}$ and Fig. $2 \mathrm{~b}$ shows the characteristic $I-V$ and $P-V$ curves of the PV panels as a function of the irradiation level $(\mathrm{G})$, where the maximum power point (MPP) is highlighted. The photogenerated current of a PV cell is proportional to the irradiation level, consequently, the generated output power strongly depends on the irradiation level; on the other hand, the voltage at the MPP presents small variations with irradiation changes, as it can be observed in Fig. 2a and Fig. 2b. As energy storage, a lithium-ion (Li-ion) battery is used at the bidirectional port with a nominal voltage of $V_{b a t}=3.6 \mathrm{~V}$ and $4.5 \mathrm{Ah}$ capacity. At the output port 8 series-connected XP-E high efficiency white LEDs from Cree are used.

In the low-power system under study, it is important to avoid any voltage drop, and therefore the use of diodes in the power flow path. Non-isolated TPC topologies for renewable energy systems have been presented $[10,11,12,13,14]$. These type of implementations need additional switches and diodes in order to configure the power flow path among the three ports. Since the application under study is a night street lighting structure, no direct sunlight conversion is required. This allows the sequential separation of the energy flows from the PV source to the battery and from the battery to the LED lighting. As a result, the conventional solution of two cascaded converters $[15,16,17]$ can be combined into a single structure with shared components as shown in Fig. 3a. Magnetic components play an important role on the converter size, price and weight. The proposed topology is a combination of two converters where the magnetic component is shared between the two operation modes by reconfiguring the power flow path depending on the availability of the energy source. Fig. 3b shows the schematic of the proposed stand-alone LtL system and Fig. 4a and Fig. 4b show the circuit configuration for the two energy flows. 


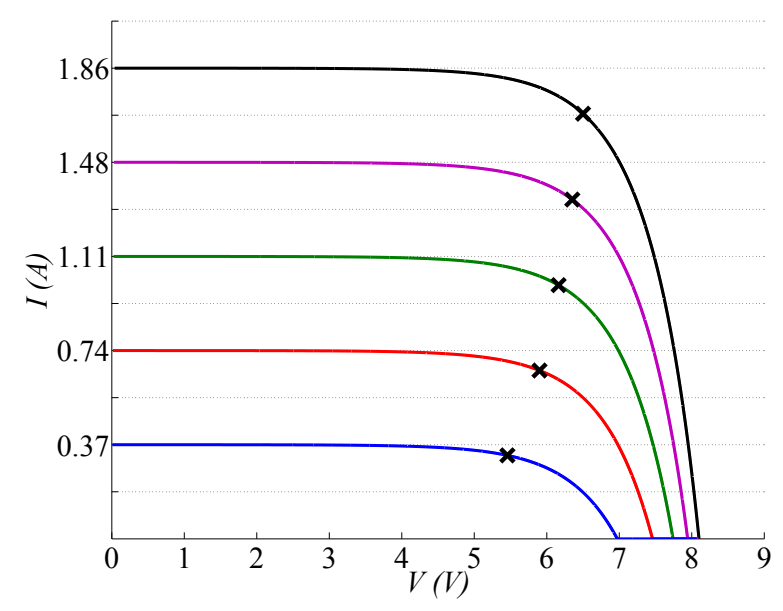

(a)

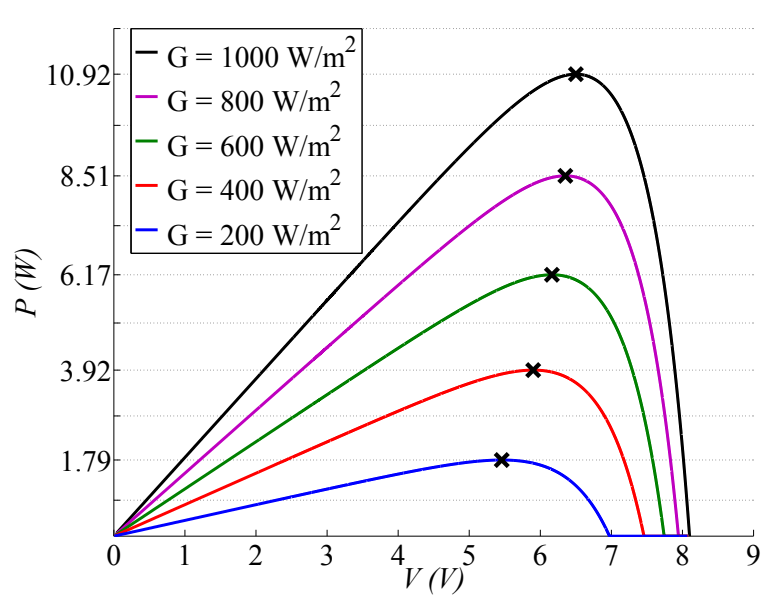

(b)

Fig. 2: PV characteristic curves for difference irradiations (G) levels (a) $I-V$. (b) $P-V$.

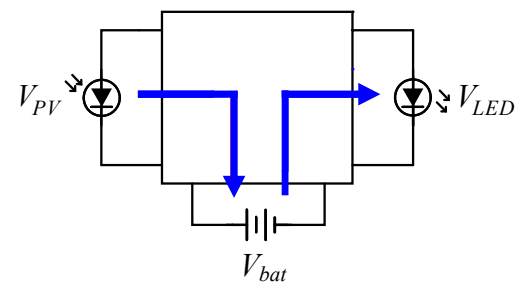

(a)

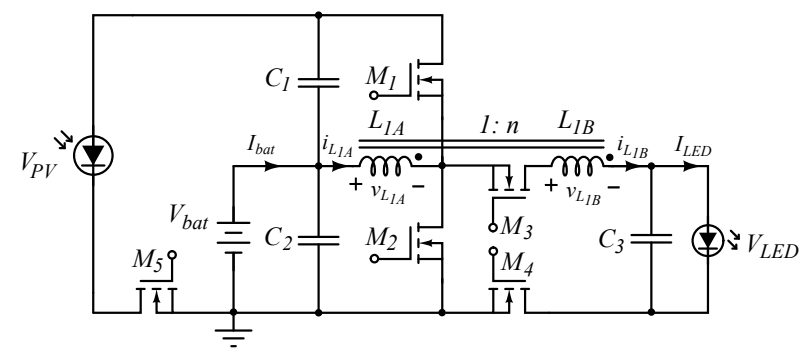

(b)

Fig. 3: Low-power stand-alone PV-LED LtL system. (a) block diagram. (b) schematic.

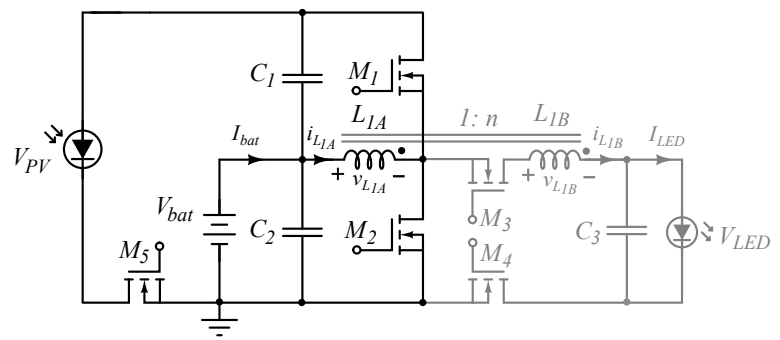

(a)

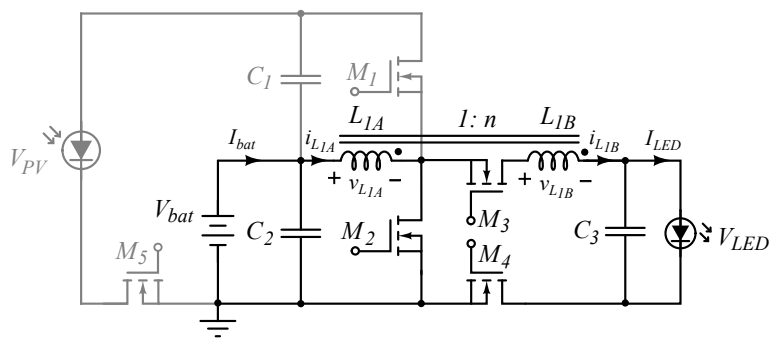

(b)

Fig. 4: Schematic of low-power stand-alone LtL system (a) (a) PV panel to battery port power flow: buck mode (b) battery port to LED power flow: tapped boost mode.

$M_{5}$ and $M_{4}$ control the power flow direction depending on the availability of the solar energy. When the renewable energy source is available, the system operates as a synchronous buck converter, as shown inFig. 4a. During the night time, the structure is configured as synchronous tapped-boost converter, as shown in Fig. 4b, to provide the high step-up ratio from the battery port to the LED output. The use of the tapped-inductor allows to avoid extreme duty cycles and high current stress in the components, which reduces switching and conduction losses. Fig. 5a and Fig. 5b shows the operating waveforms in buck and tapped boost operation modes, respectively. The proposed solution to interconnect the PV panel, the battery and the LED port makes the power stage to feature low number of components and high efficiency in both operating modes. The switches used to control the power flow path do not contribute to the converters switching losses, which are the predominant source of loss at low power level. 


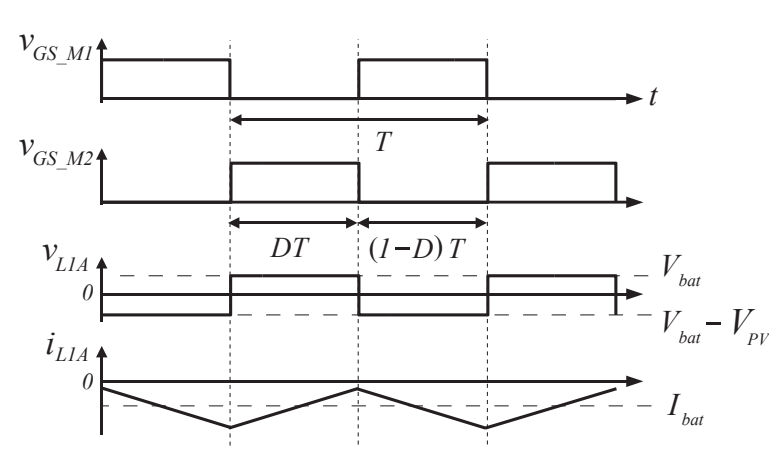

(a)

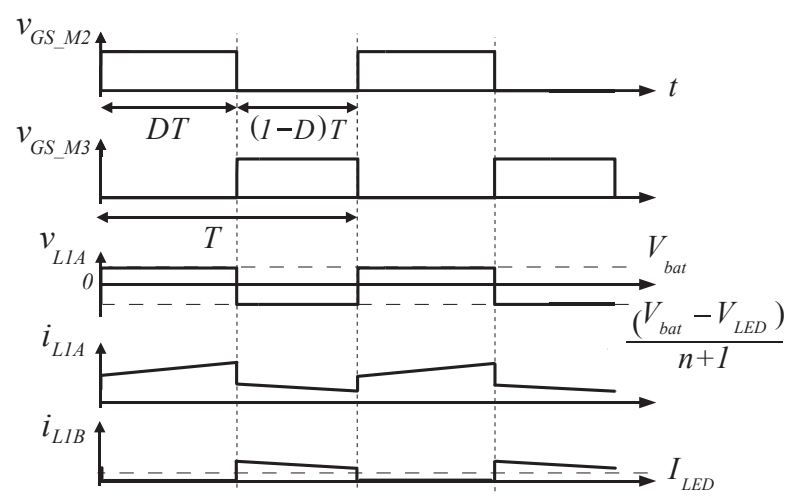

(b)

Fig. 5: LtL system operating waveforms (a) PV panel to battery port power flow: buck mode (b) battery port to LED power flow: tapped boost mode.

\section{Loss Distribution Analysis}

In this section a loss performance analysis of the power stage of the proposed stand-alone LtL system is performed. The magnetic component is determined by the specifications of the LED driver. The stage is designed to be able to drive the LED lamp at the maximum current allowed by the LED specifications. However, the LED lamp will be mostly driven at low current level, therefore, the coupled inductors structure will be optimized for operation at low power range. The tapped inductor is constructed in a n ETD29/16/10 core in material N87 from EPCOS with 7 and 35 turns for $L_{1 A}$ and $L_{1 B}$, respectively. Each of the primary layers is formed by 3 windings in parallel. The implemented winding scheme is Utype, which helps to decrease the distance between windings to reduce the leakage inductance. However, this arrangement will produce higher capacitive loss than the Z-type winding. This structure with partial interleaving winding arrangement shows the best efficiency performance at low power levels compared to the same structure with full and no interleaving and a planar magnetics ELP32/6/20 with full interleaving arrangement [18]. The coupled inductor structure leakage inductance and stray capacitances measured with an impedance analyzer Agilent 4294A are: $L_{l k}=97.44 \mathrm{nH}, C_{p}=1.04 \mathrm{nF}$ and $C_{p r i-s e c}=0.15 \mathrm{nF}$.

The inductor winding losses are divided into ac and dc resistive loses. The dc conduction losses are calculated with the squared value of the dc current and the dc resistance as (1). The dc resistance is measured with the impedance analyzer and the value for the charge and discharge intervals is $3.5 \mathrm{~m} \Omega$ and $81.2 \mathrm{~m} \Omega$, respectively. The ac conduction losses are calculated with the squared rms value of the inductor current ac component as (2). The ac resistance is measured by using the method proposed in [19], where the inductor core loss is measured using the resonant method proposed in [20] and separated from the winding loss measurement. The measured ac resistance at the converter switching frequency $f_{s w}=100 \mathrm{kHz}$ is $47.6 \mathrm{~m} \Omega$ and $1.27 \Omega$ for the charge and discharge intervals, respectively.

$$
\begin{aligned}
& P_{d c_{c o n d}}=I_{d c}^{2} \cdot R_{d c} \\
& P_{a c_{c o n d}}=I_{r m s}{ }^{2} \cdot R_{a c}
\end{aligned}
$$

The core losses are calculated using Modified Steinmetz Equation (MSE) [21] as shown in (3), (4) and (5).

$$
\begin{aligned}
& P_{M S E}=K \cdot f_{e q}{ }^{(\alpha-1)} \cdot B_{p k}^{\beta} \cdot f_{s w}\left[k W / m^{3}\right] \\
& f_{e q}=\frac{2}{\Delta B^{2} \cdot \pi^{2}} \cdot \int_{0}^{T}\left(\frac{d B}{d t}\right)^{2} d t \\
& \Delta B=\frac{V_{b a t}}{N \cdot A_{e}} D T
\end{aligned}
$$


where $K, \alpha$ and $\beta$ are the Steinmetz coefficients, $f_{s w}$ is the switching frequency, $B_{p k}$ is the peak ac flux density, $\Delta B$ is the peak to peak ac flux density, $N$ is the number of turns and $A_{e}$ is the effective area of the magnetic core.

The MOSFETs selection is performed according to the required blocking voltage in each power flow configuration. In buck mode $M_{1}$ and $M_{2}$ must withstand a maximum voltage determined by the PV open circuit voltage $\left(V_{o c}\right)$. In tapped boost mode, the main switch must block $V_{D S-M 2}=\left(n V_{b a t}+V_{L E D}\right) /(n+1)$ and the synchronous rectifier must withstand a drain-to-source voltage $V_{D S-M 3}=\left(n V_{b a t}+V_{L E D}\right)$. For the buck stage $25 V$ devices are selected for $M_{1}$ and $M_{2}$. This choice also fits the blocking voltage requirement of the shared switch $M_{2}$ in the tapped boost configuration. The synchronous rectifier selected is a $55 \mathrm{~V}$ device. In a low-power system the semiconductor gate and capacitive switching losses have a large effect on the converter efficiency, especially at low power levels. Therefore, a careful selection of the power stage switches in terms of gate charge $Q_{G}$ and output capacitance $C_{o s s}$ must be carried out. Selection of $M_{1}, M_{2}$ and $M_{3}$ is performed to achieve high efficiency at low power levels by minimizing capacitive and gate drive losses as presented in [22]. On the other hand, the power flow control devices $M_{4}$ and $M_{5}$ do not contribute to the switching loss, therefore, the selected devices aim to minimize the conduction loss. The selected MOSFETs of the power stage are: $M_{1}, M_{2}$ : BSC050NE2LS, $M_{3}$ : AUIRL024Z, $M_{4}$ : BSZ105N04NS and $M_{5}$ : IRFH4213.

The semiconductor devices can be evaluated by calculating the switching and conduction losses. The conduction losses can be calculated from the devices on-resistance specified in the manufacturer datasheet. However, the switching losses are difficult to calculate due to the circuit parasitic inductances and MOSFET input and output capacitances, $C_{i s s}$ and $C_{o s s}$, which are highly nonlinear. A measurement of the energy loss as presented in [22], provides more accurate results because the device performance can be measured at the exact operating conditions. In order to evaluate the converter switching losses a measurement of the semiconductor energy loss on the tapped boost stage is performed. Fig. 6a shows the measured switching energy loss at the turn-off event as a function of the inductor current level. Zero turn-on energy loss is obtained in this configuration due to the leakage inductance of tapped boost structure, which delays the current transition and results in zero current switching (ZCS) turn-on conditions as shown in Fig. 6b. However, the large leakage inductance of the partial interleaving arrangement has a negative impact on the main switch turn-off energy loss at high current levels as it can be observed in Fig. 6a. The semiconductor switching losses are calculated using the obtained characterization data as shown in (6).

$$
P_{s w}=f_{\text {sw }} \cdot\left(E_{\text {turn-on }}+E_{\text {turn-off }}+E_{\text {gate }}\right)
$$

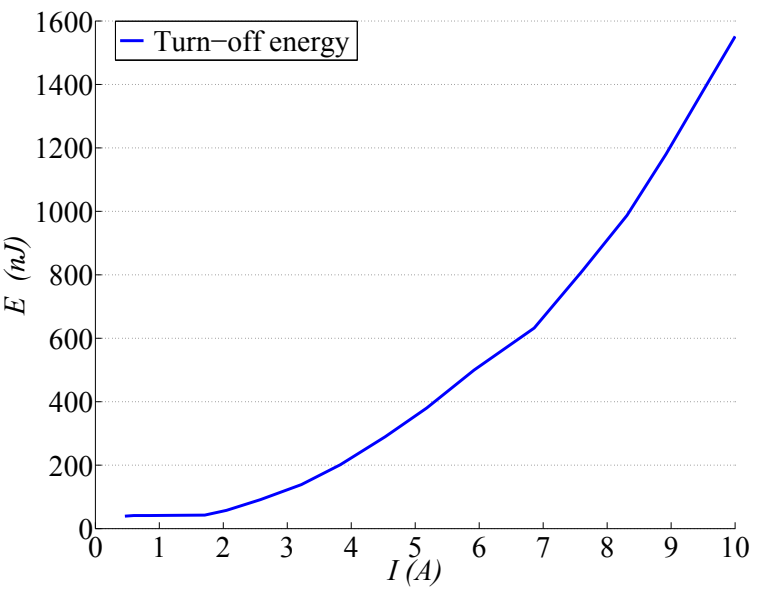

(a)

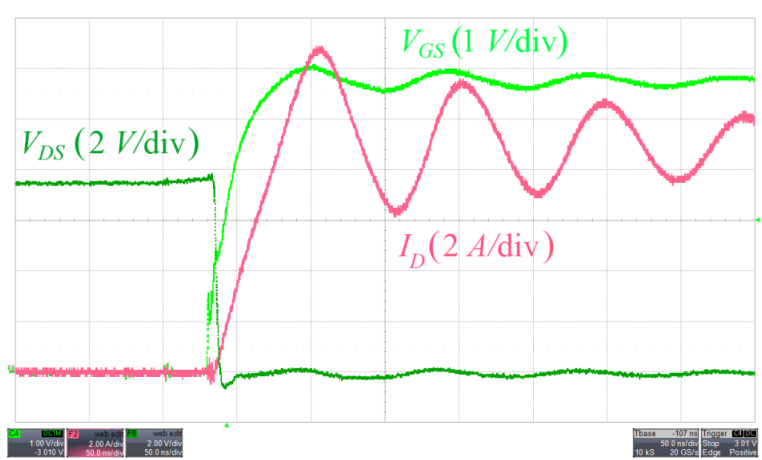

(b)

Fig. 6: Tapped boost stage (a) turn-off event measured semiconductor switching energy loss vs. inductor current level. (b) ZCS conditions at turn-on event. Drain-to-source voltage $\left(V_{G S}\right)(2 \mathrm{~V} / \mathrm{div})$, drain current $\left(I_{D}\right)(2 \mathrm{~A} / \mathrm{div})$ and gate-to-source voltage $\left(V_{G S}\right)(1 \mathrm{~V} / \mathrm{div})$. Time scale $50 \mathrm{~ns} / \mathrm{div}$. 
where $E_{\text {gate }}$ corresponds to the gate drive loss in the main switch $M_{2}$ and the synchronous rectifier $M_{3}$, which are measured in the characterization setup as $40 n J$ and $7 n J$, respectively.

The MOSFETs conduction losses are calculated with the root mean square rms of the current and the device on-resistance as in (7). The MOSFET channel on-resistance is extracted from the manufacturer component datasheet at the selected gate drive voltage value $V_{G S}=5 \mathrm{~V}$ and at $25^{\circ} \mathrm{C}$ operating temperature. The extracted values are $5.5 \mathrm{~m} \Omega, 16 \mathrm{~m} \Omega$ and $50 \mathrm{~m} \Omega$ for $M_{2}, M_{3}$ and $M_{4}$, respectively.

$$
P_{\text {cond }}=I_{r m s}^{2} \cdot R_{D S-o n}
$$

Due to the ZCS conditions caused by the coupled inductor leakage inductance, the energy loss in the magnetic component parasitic capacitances is not visible in the semiconductor switching loss characterization. This capacitive loss can be calculated using the measured stray capacitance $C_{p r i}$ and $C_{p r i-s e c}$ as shown in (8) and (9).

$$
\begin{aligned}
& E_{C_{p r i}}=\frac{1}{2} \cdot C_{p r i} \cdot\left(V_{b a t}^{2}+\left(\frac{V_{b a t}-V_{L E D}}{n+1}\right)^{2}\right) \\
& E_{C_{p r i-s e c}}=\frac{1}{2} \cdot C_{p r i-s e c} \cdot\left(n V_{b a t}+V_{L E D}\right)^{2}
\end{aligned}
$$

Fig. 7a shows the calculated efficiency loss on the coupled inductor structure as a function of the output power level. The component losses are divided in ac and dc winding loss, core loss and capacitive loss. The magnetic component is optimized to operate at low power level. At it can be observed, at high power level the ac conduction loss is the predominant loss; however, at low power level, core loss and capacitive loss need to be minimized in order to achieve high efficiency converter operation. Fig. $7 \mathrm{~b}$ shows the semiconductor losses as a function of the output power. These losses consist of switching, conduction and gate drive losses. As it can be observed, the conduction loss dominates at high power level due to the devices on-resistance. The effect of the coupled inductor leakage inductance can be observed as an increased switching loss at high power level. At low power level, the main loss contribution comes from the capacitive switching and gate loss. Moreover, it is noteworthy that the converter output voltage increases with the output power due to the characteristic LED $I-V$ curve, which makes the converter current stress to increase faster when the output power increases, further penalizing the conduction losses.

The buck stage loss distribution is next analyzed. Reutilization of the magnetic component is the key

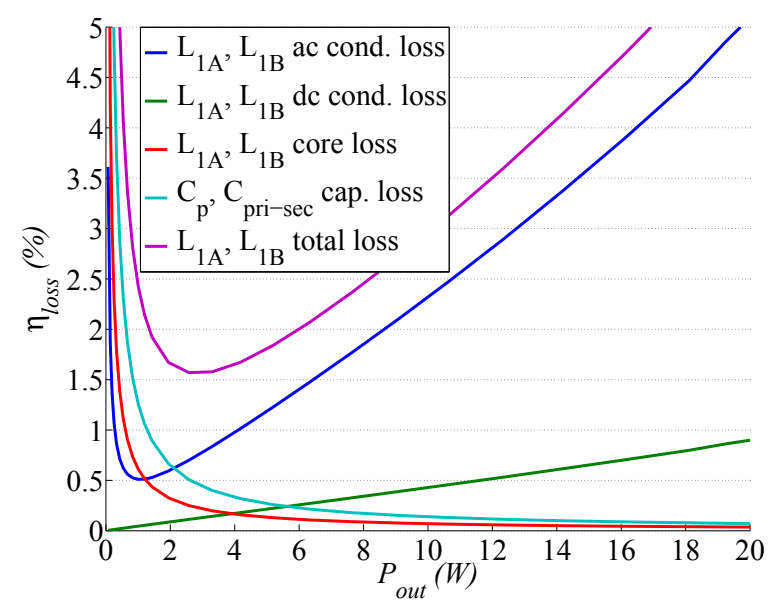

(a)

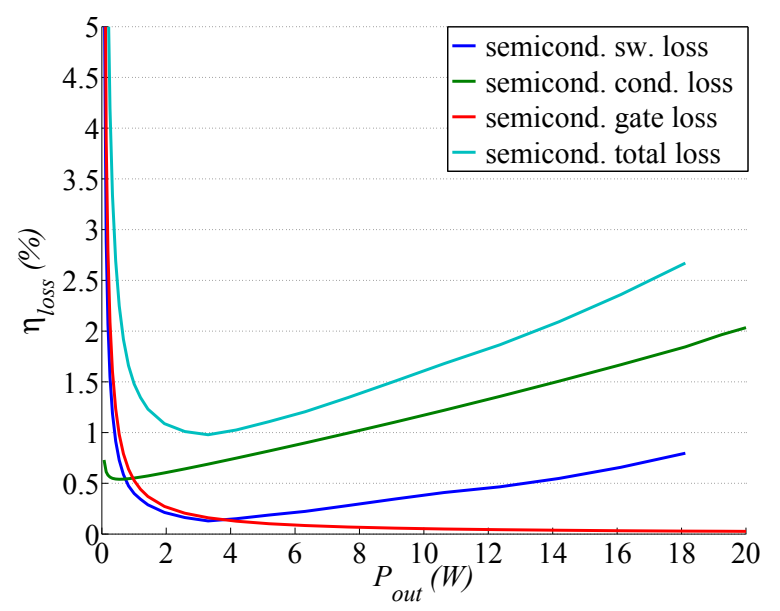

(b)

Fig. 7: Tapped boost switching cell calculated efficiency loss (a) coupled inductors $L_{1 A}, L_{1 B}$ (b) semiconductors. 
point of the proposed PV-LED structure. Inductor $L_{1 A}$ is used in the buck stage, consequently, all the parasitic capacitances of the coupled inductor structure are reflected and affect the semiconductor switching loss in buck operation mode. Therefore, selecting a low parasitic capacitance implementation for the tapped boost stage reduces the capacitive switching losses in buck operation mode, which has a positive effect on the converter efficiency at low power level. The same characterization procedure used in the tapped boost stage is applied to the buck mode stage. The switching energy of the buck stage is measured at different input voltage levels in order to account for irradiation and temperature variations in the photovoltaic panel. Fig. 8 shows the measurement of the turn-on and turn-off energy at different input voltages. The turn-off energy loss at zero current level corresponds to the energy stored on the main switch parasitic capacitance, whilst in the turn-on event represents the capacitive loss from the magnetic structure and the synchronous rectifier output capacitance. It can be observed that the switching loss energy increases with the photovoltaic input voltage due to the quadratic dependence of the stored capacitive energy and voltage. The gate drive loss energy is measured in the characterization setup as $40 \mathrm{~nJ}$ and $26 \mathrm{~nJ}$, for the main switch and the synchronous rectifier, respectively. As in the tapped boost stage, the switching loss is calculated using (6) and the characterization data from the energy loss measurement. The semiconductor conduction loss is calculated using (7) and the devices on-resistance, which is $5.5 \mathrm{~m} \Omega$ for the power stage $M_{1}$ and $M_{2}$ and $2.25 \mathrm{~m} \Omega$ for the power flow control switch $M_{5}$. Fig. 9a shows the breakdown efficiency loss for the magnetic component in buck mode. As it can be observed,

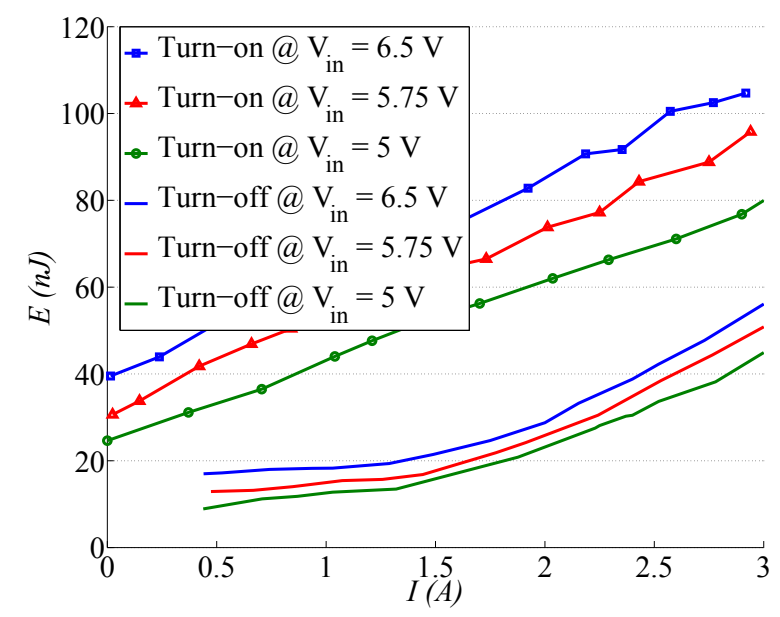

Fig. 8: Buck switching cell measured semiconductor switching energy loss at different input voltage vs. inductor current levels.

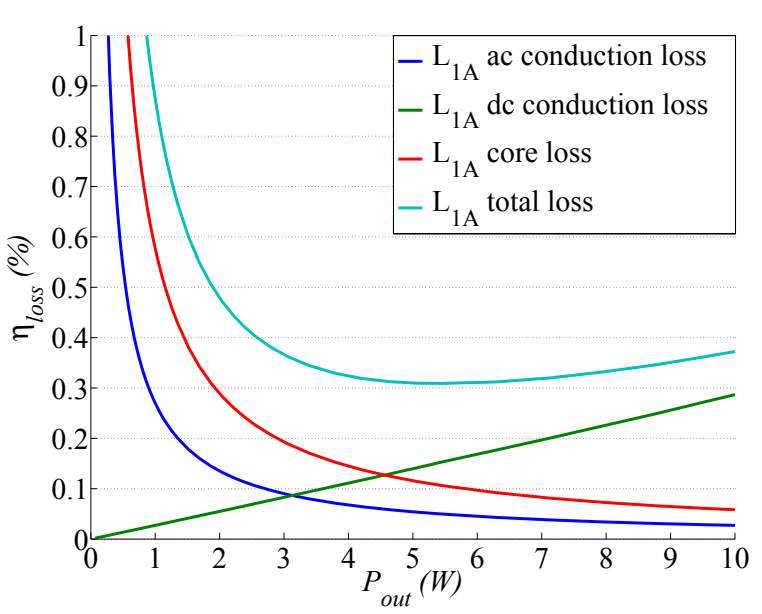

(a)

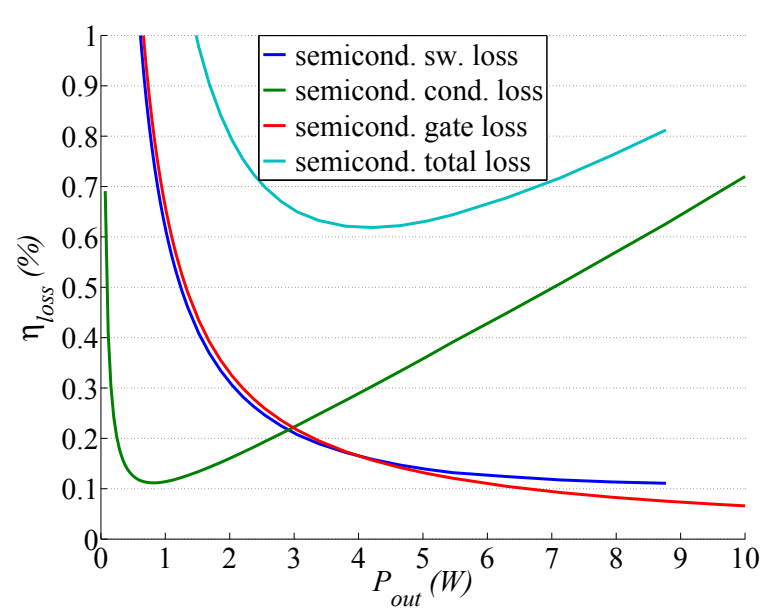

(b)

Fig. 9: Buck switching cell calculated efficiency loss (a) inductor $L_{1 A}$ (b) semiconductors. 
the core loss produces a $1 \%$ efficiency loss @ $V_{\text {in }}=6.5 \mathrm{~V}$ and $P_{\text {out }}=1 \mathrm{~W}$. This core loss could be further reduced by increasing the number of turns without having a big penalty in dc conduction loss at high power levels. However, increasing number of turns will have a negative effect on the magnetic component ac and dc conduction loss in the tapped boost stage. Fig. $9 \mathrm{~b}$ shows the switching, conduction and gate loss of the buck stage. It can be observed that gate and the switching loss have a big effect on the converter efficiency at low power levels, with $1 \%$ efficiency loss due to each of them @ $V_{\text {in }}=6.5 \mathrm{~V}$ and $P_{\text {out }}=1 \mathrm{~W}$. It has to be noticed that the device selection is based on $Q_{G}$ and $R_{D S}$ trade-off with special interest on achieving a reduced gate and capacitive loss. However, due to a limited selection of devices for low-power applications, the selected MOSFETs still possess a large die size for the selected application, resulting in a decreased performance at low power levels.

\section{Experimental results}

In order to verify the loss distribution analysis of the proposed low-power TPC a prototype of the LtL system is constructed. Fig. 10 shows the top and bottom sides of the experimental prototype. A low-power mixed-signal microcontroller MSP430F5172 is selected to digitally implement the different control loops on the power stage. The prototype is working with maximum power point tracking (MPPT) on the PV side, constant voltage (CV) and constant current (CI) control on the battery side and dimming regulation at the LED output port.

The efficiency is measured with $61 / 2$ digit multimeters Agilent 34410A. The instruments are connected and synchronized though a computer and set up with long integration time in order to ensure high frequency noise filtering and good repeatability. Efficiency curves are measured for both power flow paths as shown in Fig. 11, Fig. 12a and Fig. 12b. Fig. 11 shows the efficiency measured on the tapped boost stage together with the calculated efficiency. The measurement is performed only on the power stage and does not include the gate drive and control circuitry losses. The calculated total gate loss on this stage is $4.7 \mathrm{~mW}$. The input and output ceramic capacitor conduction losses are also included in the calculation although they have a low impact on the converter efficiency. A Hall effect current sensor is used for monitoring the battery port current, which allows implementation of the different control algorithms. This device inserts an additional dc resistance of $R_{d c}=4.5 \mathrm{~m} \Omega$ which is also included in the model. As it can be observed, the predicted efficiency shows a good match with the measured efficiency, which validates the performed loss distribution analysis of the tapped boost stage. The partial interleaving magnetic structure and the reduced semiconductor parasitic capacitances make it possible to achieve high efficiency at low power levels. In this case, a high step-up tapped boost converter with more than 97 $\%$ efficiency for output power levels in the range of $1.5 \mathrm{~W}$ to $5.5 \mathrm{~W}$ is demonstrated. Fig. 12a presents the calculated and measured converter efficiency for the buck stage operating at $V_{\text {in }}=6.5 \mathrm{~V}$. Equal than before, the input and output capacitor and the Hall effect conduction losses are included, but not the gate drive losses of the power stage, which are calculated to be $6.6 \mathrm{~mW}$. An efficiency higher than $98 \%$ is achieved from $0.7 \mathrm{~W}$ to full output power, which proves the reutilization of the primary winding of the low capacitive coupled inductor structure in a high efficient buck converter stage. Moreover, as can be seen in Fig. 12b, the converter efficiency is further increased under low input voltage condition due to the reduced capacitive losses and current stress. As it can be observed, the stage presents an efficiency

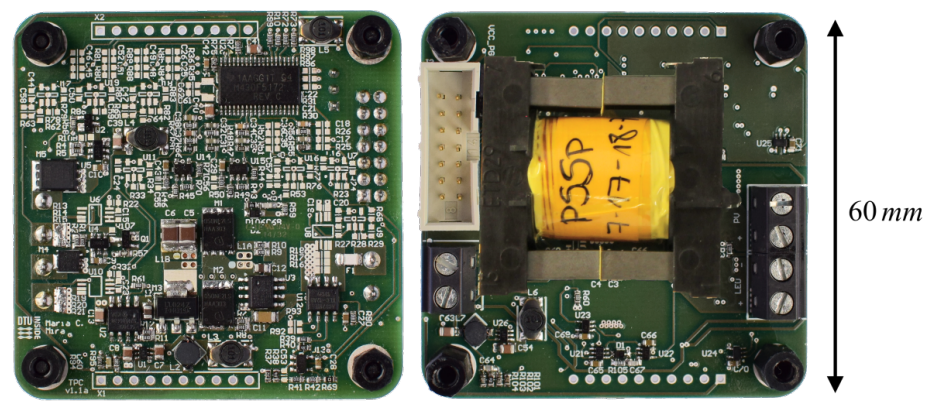

Fig. 10: Low-power stand-alone LtL prototype. 


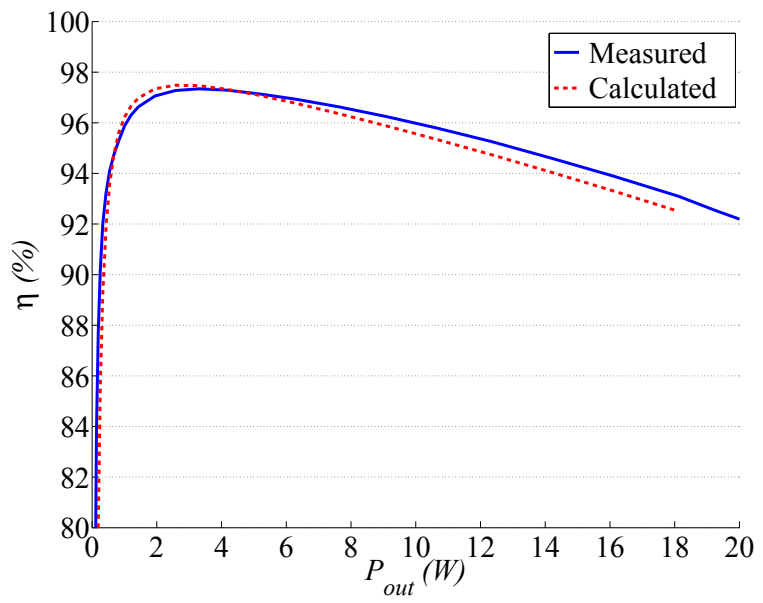

Fig. 11: Measured and calculated efficiency curves of the tapped boost switching cell.

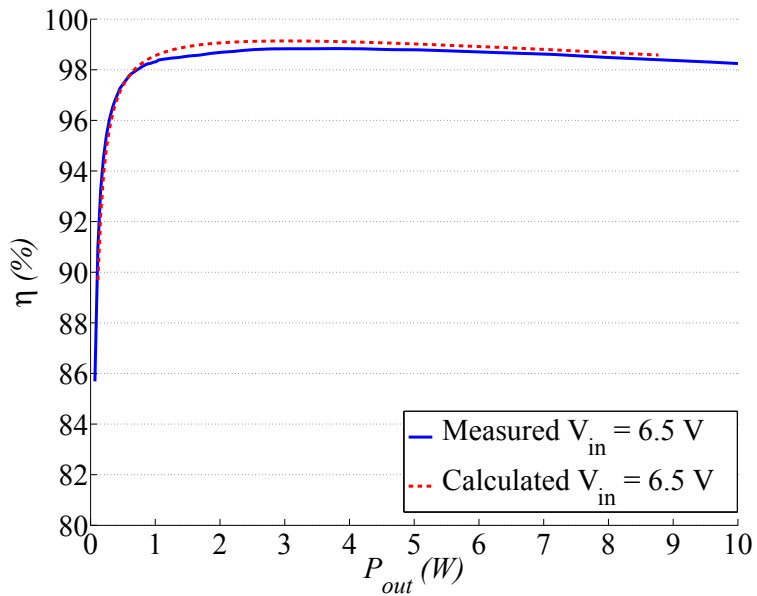

(a)

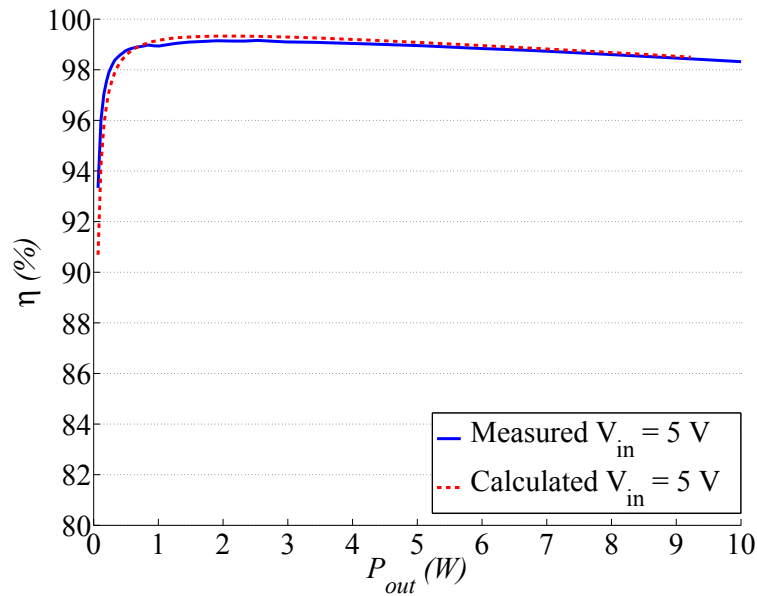

(b)

Fig. 12: Measured and calculated efficiency curves of the buck switching cell. (a) $V_{i n}=6.5 V$ (b) $V_{\text {in }}=5 \mathrm{~V}$.

over $99 \%$ from $1.2 \mathrm{~W}$ to $4 \mathrm{~W}$ output power.

As shown in Fig. 2a and Fig. 2b, low irradiation level on the PV panel corresponds to low voltage operation at the input of the converter. The designed buck stage fulfill the target of high efficiency operation at low irradiation conditions. Moreover, the LED driver stage achieves high efficiency operation at low current drive of the LED lamp. Therefore, the proposed low-power LtL structure achieves high efficiency operation in both power flow paths .

\section{Conclusion}

This paper presents a TPC topology for stand-alone low-power PV-LED systems, where no direct solar conversion is required. The key design guidelines of the LtL system are discussed and a detailed loss distribution analysis is performed. A measurement of the semiconductor switching energy loss is carried out, which allows accurate calculation of the converter switching losses. An experimental prototype is constructed and the efficiency measurements show very good match with the loss calculation, which verifies the performed breakdown analysis. In locations far from the Equator, solar powered systems are challenging due to low irradiation, and therefore, low generated power. The proposed solution features low component number and reutilization of the magnetic structure achieving high efficiency in both power flow paths. At low input voltage, which corresponds to low irradiation level, the PV to battery 
power flow shows a peak efficiency of $99.1 \%$ at $1.5 \mathrm{~W}$ output power. The tapped boost LED driver stage presents a peak efficiency of $97.3 \%$ at $3 \mathrm{~W}$ output power.

\section{References}

[1] S. S. Thale, R. G. Wandhare, and V. Agarwal, "A Novel Reconfigurable Microgrid Architecture With Renewable Energy Sources and Storage”, IEEE Transactions on Industry Appliccations, vol. 51, no. 2, pp. 1805-1816, 2015.

[2] F. Blaabjerg, Z. Chen, and S. B. Kjaer, "Power electronics as efficient interface in dispersed power generation systems, IEEE Transactions on Power Electronics, vol. 19, no. 5, pp. 1184-1194, Sep. 2004.

[3] "Data Solar Radiation. [Online]. Available: http://www.soda-is.com.

[4] "NREL-National Center for Photovoltaics-Best Research-Cell Efficiencies. [Online]. Available: http://www.nrel.gov/ncpv/.

[5] I. L. Azevedo, M. G. Morgan, and F. Morgan, "The Transition to Solid-State Lighting”, Proc. IEEE, vol. 97, no. 3, pp. 481-510, Mar. 2009.

[6] M. G. Craford, R. D. Dupuis, M. Feng, F. A. Kish, and J. Laskar, "50th Anniversary of the Light-Emitting Diode (LED): An Ultimate Lamp [Scanning the Issue]", Proc. IEEE, vol. 101, no. 10, pp. 2154-2157.

[7] D. Park, Z. Liu, and H. Lee, "A 40 V 10 W 93 \% Efficiency Current-Accuracy-Enhanced Dimmable LED Driver With Adaptive Timing Difference Compensation for Solid-State Lighting Applications", IEEE Journal of Solid-State Circuits, vol. 49, no. 8, pp. 1848-1860, Aug. 2014.

[8] C. Moo, Y.-J. Chen, and W. Yang, "An Efficient Driver for Dimmable LED Lighting", IEEE Transactions on Power Electronics, vol. 27, no. 11, pp. 4613-4618, Nov. 2012.

[9] A. Pollock, H. Pollock, and C. Pollock, "High Efficiency LED Power Supply", IEEE Journal on Emerging and Selected Topics on Power Electronics, vol. 3, no. 3, pp. 617-623, Sep. 2015.

[10] H. Wu, K. Sun, S. Ding, and Y. Xing, “Topology Derivation of Nonisolated Three-Port DC-DC Converters From DIC and DOC", IEEE Transactions on Power Electronics, vol. 28, no. 7, pp. 3297-3307, Jul. 2013.

[11] Y. Hu, W. Xiao, W. Cao, B. Ji, and D. J. Morrow, "Three-Port DC-DC Converter for Stand-Alone Photovoltaic Systems", IEEE Transactions on Power Electronics, vol. 30, no. 6, pp. 3068-3076, Jun. 2015.

[12] Y. Chen, A. Q. Huang, and X. Yu, "A High Step-Up Three-Port DC-DC Converter for Stand-Alone PV/Battery Power Systems", IEEE Transactions on Power Electronics, vol. 28, no. 11, pp. 5049-5062.

[13] T. Cheng, D. D. C. Lu, A. Gong, and D. Verstraete, "Analysis of a three-port DC-DC converter for PVbattery system using DISO boost and SISO buck converters", Australasian Universities Power Engineering Conference (AUPEC), 2015, pp. 1-6.

[14] L. Chien, C. Chen, J. Chen, S. Member, and Y. Hsieh, "Novel Three-Port Converter With High-Voltage Gain", IEEE Transactions on Power Electronics, vol. 29, no. 9, pp. 4693-4703, 2014.

[15] N. Femia, M. Fortunato, and M. Vitelli, "Light-to-Light: PV-Fed LED Lighting Systems", IEEE Transactions on Power Electronics, vol. 28, no. 8, pp. 4063-4073, Aug. 2013.

[16] C. Hua and P. Ku, "Implementation of a Stand-Alone Photovoltaic Lighting System with MPPT, Battery Charger and High Brightness LEDs", International Conference on Power Electronics and Drives Systems (PEDS), 2005, vol. 2, pp. 1601-1605.

[17] M. A. D. Costa, G. H. Costa, A. S. dos Santos, L. Schuch, and J. R. Pinheiro, "A high efficiency autonomous street lighting system based on solar energy and LEDs", Brazilian Power Electronics Conference (COBEP) 2009, pp. 265-273.

[18] M. C. Mira, A. Knott, and M. A. E. Andersen, "Analysis and comparison of magnetic structures in a tapped boost converter for LED applications", International Power Electronics and Application Conference and Exposition (PEAC), 2014, pp. 594-599.

[19] M. Mu and F. C. Lee, "Comparison and optimization of high frequency inductors for critical model GaN converter operating at $1 \mathrm{MHz}$ ", International Electronics and Application Conference and Exposition (PEAC), 2014, pp. 1363-1368.

[20] M. Mu, Q. Li, D. J. Gilham, F. C. Lee, and K. D. T. Ngo, "New Core Loss Measurement Method for HighFrequency Magnetic Materials”, IEEE Transactions on Power Electronics, vol. 29, no. 8, pp. 4374-4381.

[21] I. Villar, U. Viscarret, I. Etxeberria-Otadui, and A. Rufer, "Global Loss Evaluation Methods for Nonsinusoidally Fed Medium-Frequency Power Transformers”, IEEE Transactions on Industrial Electronics, vol. 56, no. 10, pp. 4132-4140, Oct. 2009.

[22] M. C. Mira, A. Knott, and M. A. E. Andersen, "MOSFET loss evaluation for a low-power StandAlone photovoltaic-LED system, IEEE 11th International Conference on Power Electronics and Drive Systems (PEDS), 2015, pp. 779-785. 